\title{
MILK MARKETING AND DAIRY VALUE CHAIN DEVELOPMENT IN NEPAL IN RELATION WITH CLIMATE RESILIENCE EFFORT IN THE PRESENT CONTEXT
}

\author{
B. Sharma* \\ Ministry of Livestock Development, Singhadurbar, Kathmandu \\ (*email:banshi.sharma@ymail.com)
}

\begin{abstract}
Nepal is agricultural country with a special focus on dairy sub-sector. Almost $80 \%$ of milk in market, which have been produced by small holder farmers with a well- developed dairy value chain. Ministry of Livestock Development (MoLD) has given due importance for milk production providing support on feed and forage programs to the farmers as well as introducing crossbreeding programs to uplift the genetics of local cattle and buffaloes. By 2018, the country shall be selfsufficient in milk production, where the requirement of 91 lit of milk per person per year is expected to be achieved. Foot and Mouth Disease (FMD) emerges as a major health hazard in dairy sector apart from Hemorrhagic Septicemia (HS) and black quarter (BQ). The incidence of clinical and subclinical mastitis is still high in dairy pocket areas. Moreover, the seasonal fluctuation of milk production is hampering the growth of dairy sector. The need of product diversification and powder milk production are of immense important in long run to sustain dairy sub-sector in Nepal. MOLD has given priority for four pillars for livestock development namely animal feed, animal breeds, animal health and livestock marketing. That sector on balanced development program will lead to increase on milk, meat, eggs, nutrition, and food security in the nation.
\end{abstract}

Keywords: dairy sub-sector, dairy value chain, milk production, pocket areas

\section{BACKGROUND}

Agriculture contributes $31.6 \%$ on GDP and the share of livestock sector on agricultural GDP is 26.62\% (Sharma, 2007).The contribution together with production of food (meat, milk, and eggs), fibre, hides/skins and transportation amounts to about 15\% of GDP which is $31 \%$ of Agricultural GDP (LMP, 1993) and 51 per cent of this contribution is derived from the hills, 38 per cent form Terai and 9 per cent from the mountains (APP, 1995). Therefore, livestock forms an integral part of agricultural production system in Nepal. Among different livestock, dairy breeds of cattle and buffaloes are popular in Nepal. In case of small ruminants, meat breeds of goat and sheep reared in mountains, hills and Terai region of Nepal (Sharma, 2002). Livestock population, in relation to arable land and animals per person, are large by Asian standards, with approximately 7.2 million cattle, 5.2 million buffalo, 9.7 million goats, and 0.8 million sheep (MOAD, 2011/2012). Animal feed has been one of the major production inputs drawing attention of the producers as it alone shares nearly 50-60 percent of the production cost of milk and meat from ruminants (Sharma, 2007).

Agricultural by-products and forages are the major feed resources in Nepal. Winter forage crops (oat, vetch, berseem and fodder pea) and perennial forage species (Napier, Stylo, Molasses, molato 
etc.) on marginal lands are increasing each year. About 0.1 percent of the cultivated land brought under forage cultivation and over 4,000 ha of pasturelands have already been improved (Pande, 1994). Among the cultivated forage crops, oat is the main fodder crop that can fit with the existing mixed crop livestock farming systems in Terai and hill zones (Upreti, 2005). However, rice production is the Nepal's most important crop amounting to about half of the total cereal grains produced in the country (Ghimire et al., 2013). Rice by-products like straw plays a vital role in livestock production system in Nepal as an alternative to the green forages during the lean season. Apart from rice straw, there has been use of husk, rice polish, and de-oiled rice polish in cattle feed. The production of rice has been increased by $21.66 \%$ as compare of 2015 . At present, the production of rice is 52, $30000 \mathrm{MT}$ on an area of 15, 52469 hectre (MOAD, 2016 report) yielding 5,972,823 MT straw (Source: Rice Varietal Mapping in Nepal: Implication for Development and Adoption Published by Crop Development Directorate, August 2015). The cost of rice straw alone in animal feed is NRs 53.75 billion which is a huge amount that has been spent on animal feed (MoLD, 2016).

Agriculture is mostly rain-fed and dominated by subsistence farming systems. In recent years, increase in both flood and drought conditions have been observed. Undoubtedly, changes in climatic factors have substantial impact at the local level as they change the agro ecosystem, resulting in loss of land, livestock and household assets (Pant 2011). The warmer climate is expected to lead to a higher intensity of extreme weather events increasing the risk of flash floods in parts of Nepal. Available studies offer differing estimates of the impact on crop production in Asia from increasing temperature and water stress due to unobserved characteristics of crosssectional units, lack of information on agricultural production, and ignorance in price variation and carbon fertilization effects (Mendelsohn, 2000).

The low production of high nutritious grass in dry spring season may lead to less nutrition to the farm animals. The pattern of calving season in buffaloes may have impact on milk production. Availability of water is less in dry warm season and hence effects on dairy value chain.

\section{INTRODUCTION}

Livestock is an integral part of agricultural production system in Nepal. Animal feed forms the major part in any production system as it covers the major share in the overall production cost (Sharma, 2007). There is excess green forage available during the monsoon period, but for the remaining six months, over the winter and spring, there is a lack of feed. The commercialized farms compensate these shortages by supplementing livestock with expensive concentrate feeds. Moreover, adoption of livestock insurance by farmers has started gaining pace. In insurance premium collection, livestock has $80 \%$ contribution and remaining $20 \%$ is obtained from crops and vegetable sector. Government of Nepal $(\mathrm{GoN})$ has provided $75 \%$ subsidy on premium for insurance program, which benefited to dairy farmers. However, the poor transport network round the year is still one of the major hurdle for dairy farmers in Nepal. There is immense need of product diversification of dairy such as establishment of milk powder plant of 100,000 lit per day capacity, which will be beneficial to the farmers to lower milk holidays during the flush season. There is also a need to establish milk collection schedule twice a day. It will enhance the quality of milk. The Ministry of Livestock Development (MoLD) has decided to launch four pillars for betterment of livestock practices in Nepal i.e. animal health, livestock breed, animal feed and livestock market 
and it is of utmost importance to maintain balance between four pillars for robust growth in livestock sector.

\section{Present status}

At present, the milk production per year in Nepal is 1800000 MT (MOLD, 2016) of which 20\% goes to market from formal sector and rest $80 \%$ is sold in local markets and used for household consumption. Of the total milk produced, $70 \%$ is obtained from buffaloes and $30 \%$ comes from cows. The milk production from buffalo is very much seasonal, whereas cow milk is available round the year in similar pace. Currently, the availability of milk is 71 lit / head/year. The MoLD has 40 points commitments to increase the milk production to reach 91 litre per head per year within 3 years' time (MOLD, 2016).

Based on four pillars, the present status of dairy sector can be described as follows:

1. Animal health- The herd health is important for producing optimum level of milk from improved cattle and buffaloes. Foot and Mouth Disease (FMD), Haemorrhagic Septicemia (HS), Black Quarter (BQ) are some of the important infectious diseases in dairy cattle and buffaloes. Therefore, there has been national FMD control project focusing on vaccination of animals in dairy pockets of the country. HS and BQ vaccination has been done by district livestock services office under devolved program. Similarly, liverfluke is the major problem in low lands, hills and Terai of Nepal. Periodic de-worming campaign and awareness program has been implemented in the country. There is a need for enhancing bio-security of the farms along with improved laboratory facilities.

2. Livestock breeds: Murrah buffalo is the major exotic breed in Nepal. There are $38 \%$ of crossbred buffaloes in Nepal. Similarly, Lime, Parkote and Gaddi breeds of buffaloes are also doing well in western part of Nepal giving good yield of milk. Jersey is the major exotic breed in Nepal followed by Holstein-Friesian. There are $25 \%$ of cross-bred cattle in Nepal. DLS focus on cross breeding with Jersey in hill and mountain regions. There is cross breeding with Holstein-Friesian in Terai and hill region. The local cattle have potential of 300 litres of milk per lactation and exotic cross bred cows give 2400 litre per lactation whereas improved buffaloes give 1500 litres of milk per lactation (MoLD, 2016).

3. Animal feed: There is excess green forage available during the monsoon period, but for the remaining six months, over the winter and spring, there is a lack of feed. In commercialized farming situations, farmers compensate shortages of forages with supplementation of expensive concentrate feeds. As concentrates are expensive, animals are not fed to their requirement which increases costs without significant increase in production. This has serious implications for competitiveness of the local products against imported products and for the sustainability of livestock production systems. There has been forage mission program focusing on improving forage production in farm level which promotes implication of the strategies to produce forage round the year and emphasizes on hay and silage making. Currently, the program covers 50 districts of the country. There is production of 1400 MT to 1800 MT of feed per day in Nepal of which $80 \%$ has been used in poultry feed and rest $20 \%$ has been utilized for cattle feeding. Rice bran has been used $30 \%$ in cattle feed and $10 \%$ in poultry feed generally (personal communication with animal feed association of Nepal). 
4. Livestock market: Livestock market promotion directorate (LMPD) has mandate for dairy marketing program under DLS. LMPD distributes 500 litres, 1000 litres and 2000 litres chilling vat on $70 \%$ subsidy based on the need of the milk cooperatives. There are 1855 milk marketing cooperatives in Nepal. In the policy of dairy sector, there is National Dairy Development Board (NDDB). It relays on policy guidelines of MoLD and Dairy policy-2064 BS.

\section{Future Potentials}

Based on four pillars, the future course of action on dairy sector can be described as follows:

1. Animal health: The herd health is important for producing optimum level of milk from improved cattle and buffaloes. Nepal is focusing on progressive control and eradication of FMD from Nepal and regional cooperation is required to eliminate FMD from South Asia. National FMD control projects are focusing on vaccination of animals in dairy pocket areas. FMD vaccination campaign shall be continued which shall cover major dairy pockets of the country so that the number of outbreaks will be reduced. HS and BQ vaccination has been done by district livestock services office under devolved program. The program will be continued in major livestock pocket areas to reduce number of outbreaks. Similarly, liverfluke is the major problem in low lands, hills and Terai of Nepal. Periodic de-worming campaign and awareness program has been implemented in the country and shall be continued.

2. Livestock breeds: Murrah buffalo is the major exotic breed in Nepal. There is a need of increasing up to $70 \%$ of cross bred buffaloes in Nepal. Similarly, Lime, Parkote and Gaddi breeds of buffaloes should be preserved and the best of those animals shall be identified, and semen collection shall be done for artificial insemination (AI) in native areas of such buffaloes in western part of Nepal. Local buffaloes are also giving good yield of milk with higher fat \%. Jersey is the major exotic breed in Nepal followed by Holstein-Friesian. There should be $50 \%$ of cross bred cattle in Nepal. DLS will focus on more milk production from cows so that self sufficient mark of 260,0000 MT of milk can be produced in Nepal. Dairy cattle and buffaloes resource centre establishment program has been created in potential districts of Nepal.

3. Animal feed: There has been forage mission program focusing on Forage Resource Centre (FRC) one in each district. Propagation of forage seeds, saplings, slips are very much important. There is need for fodder tree cultivation program in mid hills, hill and mountain regions. The raw materials of feed shall be harvested by Ministry of Agriculture Development (MoAD) in close collaboration with MoLD. Therefore, Nepal can save millions of scarce foreign currencies. The consumption of milk is increasing, and it creates large demand of forage and feed which shall be provided from agricultural land and agro-forestry policy will also focus on animal forage and pasture issues.

4. Livestock market: There are 1855 milk marketing cooperatives in Nepal. $45 \%$ of dairy marketing has been done by Dairy Development Corporation (DDC). Private dairy has 55\% share in the market. The quality milk production and consumers' choice is very much limited due to unavailability of milk in required amount round the year in city and metropolitans. Therefore, the quality of milk has been compromised from farm level itself although MoLD has initiated quality milk production and better supply chain from farm to table. Moreover, NDDB has limited role and 
responsibilities. There is more transparent role of NDDB dairy market research. The LMPD shall focus on milk transportation vehicle support, focus on processing of milk and clean milk production for marketing.

\section{CONCLUSIONS}

1. Agriculture makes up 31.6 percent of the GDP and livestock accounts for 26.9 percent of agricultural GDP Nearly 70 percent of the population engaged in agriculture keeps livestock. The Agriculture Development Strategy(ADS), 2015(2015-2035), which will guide Nepal's agriculture program for the next 20 years, assigns livestock a key role, both as an engine of agricultural and economic growth and as a source for reducing poverty and improving food and nutrition security. The ADS aim at achieving "self-reliant, sustainable, competitive and inclusive agriculture sector that drives economic growth, and contributes to improved livelihoods and food and nutrition security". To achieve the vision, the ADS will accelerate agriculture sector growth through good governance, productivity, profitable commercialization and competitiveness. The ADS recognize that the productivity and competitiveness of the agricultural sector in the long run will depend on the access and adoption to improved technology, smart advisory services, and engagement of private sector and institutional capacity building to achieve total factor productivity increase. The robust livestock and dairy marketing along with value chain are in high importance.

2. Demand for livestock and livestock products, and particularly milk and meat, has outstripped supply in Nepal, causing increasing reliance on imports. This mounting dependence on imports diverts scarce foreign exchange. At the national level, urban demand for milk and meat are met by average annual imports of nearly 10,500 metric tons of dairy products ( $\$ 14$ million value), 476,000 live goats and 150,000 buffalo annually (DLS, 2010); representing NR6 billion a year on meat imports and NR8.61 billion a year on milk imports.

3. Limited institutional capacity, extension and outreach services which are limited in their capacity to reach smallholder producers, and underdeveloped value chains have undermined the livestock sector in its potential to capitalize on local demand and to both substitute livestock-based imports and generate export revenue. Weak extension and outreach services are a serious impediment to livestock sector growth in Nepal. Extension services tend to end at the District or village Development Committee level, leaving a huge gap between farmers and extension centers. The Livestock Service Centers have remained largely ineffective due to the lack of basic diagnostic facilities, budget, and trained human resources. While the use of ITs have been gaining momentum in the region, Nepal has yet to capitalize on it despite a very well established mobile phone service network and internet facilities in the country. Modernized services and competitive production systems have been key to vitalize the livestock sector by the ADS (2015).

4. The (2015-2035) Agriculture Development Strategy of the Government of Nepal has identified institutional capacity building as one of the key instruments to lead livestock development. The newly established Ministry of Livestock Development announced by the government on 24 December 2015 will be responsible for delivering an evidence-based sector strategy, policies, and acts. Fulfilling this mandate will require significant capacity on the part of the Ministry, as well as the development of an appropriate legal and regulatory framework such as the food quality and safer commerce and trade, and public enterprise reform. The Nepalese products 
have been facing non-tariff barriers in the form of sanitary and phyto-sanitory and technical standards in the export market such as Yak cheese products into the bordering town in India and China.

5. Livestock remains a predominantly smallholder enterprise in Nepal, with most of the production geared toward subsistence or sub-commercial purposes targeted at local markets. The ongoing analytical work has identified meat and dairy production as potential drivers of economic growth in Nepal. While several private companies operate in the dairy sector the lack of road access to urban areas has discouraged private investment in areas where the bulk of milk and meat is produced, preventing most producers from linking into value chains. Lack of access to affordable financing, credit, and information services have made it difficult for the private sector to establish and operate milking centers, processing plants, and other commercial operations. The lack of live livestock markets/auction sites and hygienic slaughter houses are additional impediments to livestock and livestock product development. Transforming dairy and meat production into a modern, economically viable and environmentally sustainable sector will require a value chain approach that aggregates and mainstreams smallholder producers into the supply chain. In addition, there is a need for restocking to replace livestock losses during the earthquake. This provides an opportunity to introduce improved-breed animals. Restocking will be done after carefully assessing the carrying capacity to ensure a good balance between the number of animals and environmental considerations.

6. Nepal is vulnerable to climate related risk. Nepal has an extremely diverse and complex climate with niche weathers in various regions. The GCM projections shows a multi-model mean of $1.4{ }^{\circ} \mathrm{C}$ increase in temperature in Nepal by the 2030 , with the range of $0.5-2.0{ }^{\circ} \mathrm{C}$. The models also predict a -14 to $40 \%$ change in precipitation in monsoon and increase in heavy precipitation event by the 2030s. Some of these predictions have already observed in terms of increased rainfall variability, increased winter drought, increased number of dry days in pre- and post-monsoon seasons. Climate change has and will continue to affect the largely rain-fed and traditional agriculture sector, leading to large annual variations in crop and livestock production. In addition, climate change is likely to increase the frequency of the weather-related hazards, which will also have its toll on agriculture production. Efforts to increase climate-resilience in rural communities and the agricultural sector more broadly must now be scaled up along with earnest operationalization of climate adaptation strategies at the local levels. The livelihood of more than 80 percent of local populations in the hilly regions is heavily dependent on climate sensitive areas such as agriculture and livestock. Lack of access to climate risk insurance, climatic information and agricultural techniques have denied the farmers opportunities to use climate smart innovations and thus exposing them to greater risks. At a global scale livestock is a significant contributor to climate change, and for Nepal, given its exposure to climate related events, modernization of the livestock sector must necessarily consider opportunities to attain production efficiencies which will positively affect the sector's GHG emissions by tapping into the wide range of climate-smart practices and technologies.

7. Developing the livestock sector offers opportunities to address gender disparities and tackle nutrition challenges. FAO estimates that nearly 70 percent of the population engaged in agriculture keep livestock and women provide more than 70 percent of the labor. With a rapidly 
growing market for meat, dairy and dairy products, the livestock sector provides significant scope and opportunity to engage/retain men, women and youth. In the high mountains, potential for development of cashmere fiber production exist which has an established brand name in the global market. Furthermore, the malnutrition rate in Nepal is alarmingly high with stunting of children under five at 37.4 percent, underweight at 30.1 percent, and wasting at 11.3 percent. Consumption of animal source food during the first 1000 days of a child's life is critical to the physical and mental wellbeing of the child. Thus, the investment in the livestock sector will not only help increase income, employment and import substitution, as well as opportunities for returnee migrant workers, it will also help address nutrition deficiency.

\section{REFERENCES}

Agriculture Prospective Planning, (1995), Agriculture Project Services Centre, Singhdurbar/John Meller Associates, Washington DC, USA.

Annon (2015), Rice Varietal Mapping in Nepal: Implication for Development and Adoption Published by Crop Development Directorate, August 2015).

DLS (2011), Annual publication from Department of Livestock Services, Hariharbhawan.

DLS (2010), Annual publication from Department of Livestock Services, Hariharbhawan.

Ghimire, S, Dhungana, S.,Krishna, V.V., No. Teufel; Sherchan, DP (2013) Biophysical and socioeconomic characterization of cereal production systems of Central Nepal. Socioeconomics Program Working Paper 9. Mexico, D.F., CIMMYT

IPCC (Intergovernmental Panel on Climate Change) (2007) Luttrell, C; Schreckenberg, K; et al. 2007. The implications of carbon financing for pro-poor community forestry. Forestry briefing. Contribution of Working Group III to the Fourth Assessment Report of IPCC. London, Overseas Development Institute

Joshi, B.R., (1992) The Role of Large Ruminants. Sustainable Livestock Production in the Mountain Agro-ecosystem of Nepal, FAO Animal Production and Health Paper 105.

LMP (1993) Livestock Master Plan. The livestock Sector Volume III, Asian Development Bank /ANZDECK /APROSC.

Mendelsohn, R. (2000) Measuring the Effect of Climate Change on Developing Country Agriculture. FAO Economic and Social Development Paper 145. ISBN: 925104470B. http://www.fao.org/docrep/003/X8044E/x8044e04.htm

MOAD (2011/2012). Statistical information on Nepalese Agriculture. Agribusiness Promotion and Statistics Division, Singh Durbar, Kathmandu, Nepal.

MOLD (2016) Annual report of Ministry of Livestock Development, Singhdurbar, Kathmandu.

Morton, J.F. (2007) The impact of climate change on smallholder and subsistence agriculture. PNAS 104: 50, 19680- 19685. http://www.pnas.org/content/104/50/19680

Pande, R.S. (1994) Opportunities for fodder and pasture development and promising species in Nepal, II National Conference on science and Technology. RONAST, 8-11 June 1994, Kathmandu.

Pant, K.P. (2011) Economics of climate change for smallholder farmers in Nepal: a review. The Journal of Agriculture and Environment,12: 113-126

Pariyar, D. (2002). Fodder oats in Nepal. Proceedings of the fifth meeting of the the Temperate 
Asia Pasture and Fodder Network(TAPAFON), RNR Research Centre Bajo, Wangdue, Bhutan, 30 April-4 May, 2002, pp 167-180.

Sharma, B. (2002). Role of improved livestock farming for preserving natural resources and limits the impact of climate change, Agriculture and Environment, pp 72-75.

Sharma, B. (2007). Improved livestock farming and animal feed security in Nepal to minimize environmental degradation.

Sharma, B. (2016), Present status and future strategy of forage development in Nepal, Agriculture and environment, published by MoAD, Singhdurbar.

Upreti, C.R. (2005). Livestock feeding systems and the place of fodder oats in Nepalese systems. Proceedings of the Workshop on Fodder Oats, Fodder Technology Packages and Small Farm Income Generation, Kathmandu, Nepal, 8-11 March, pp 77-82. 